\title{
Vaginal self-sampling is a cost-effective way to increase participation in a cervical cancer screening programme: a randomised trial
}

\author{
K Haguenoer ${ }^{\star 1,2}$, S Sengchanh ${ }^{2}$, C Gaudy-Graffin ${ }^{3,4,5}$, J Boyard ${ }^{2}$, R Fontenay ${ }^{6}$, H Marret ${ }^{4,7}$, A Goudeau ${ }^{3,4,5}$, \\ N Pigneaux de Laroche $^{8}$, E Rusch ${ }^{4,6,9}$ and B Giraudeau ${ }^{1,4,10}$ \\ ${ }^{1}$ INSERM, U1153, Paris, France; ${ }^{2}$ Cancer Screening Department, CHRU de Tours, Tours 37000, France; ${ }^{3}$ Department of \\ Bacteriology and Virology, CHRU de Tours, Tours 37000, France; ${ }^{4}$ Université François-Rabelais de Tours, PRES Centre-Val de Loire \\ Université, Tours 37000, France; ${ }^{5}$ INSERM U966, Tours 37000, France; ${ }^{6}$ Medico-Economic Evaluation Unit, CHRU de Tours, Tours \\ 37000, France; ${ }^{7}$ Department of Gynaecology and Obstetrics, CHRU de Tours, Tours 37000, France; ${ }^{8}$ Virology Laboratory, Inter- \\ Regional Health Institute, Tours 37000, France; ${ }^{9}$ Université François-Rabelais, Équipe émergente de recherche Éducation, Éthique, \\ Santé, Tours, France and ${ }^{10} \mathrm{CHRU}$ de Tours, INSERM CIC1415, Tours 37000, France
}

Background: Cervical cancer screening coverage remains insufficient in most countries. Our objective was to assess whether in-home vaginal self-sampling with a dry swab for high-risk human papillomavirus (HR-HPV) testing is effective and cost-effective in increasing participation in cervical cancer screening.

Methods: In March 2012, 6000 unscreened women aged 30-65 years, living in a French region covered by a screening programme, who had not responded to an initial invitation to have a Pap smear were equally randomised to three groups: 'no intervention'; 'recall', women received a letter to have a Pap smear; and 'self-sampling', women received a self-sampling kit to return to a centralised virology laboratory for PCR-based HPV testing.

Results: Participation was higher in the 'self-sampling' than in the 'no intervention' group $(22.5 \%$ vs $9.9 \%, P<0.0001 ;$ OR 2.64$)$ and 'recall' group (11.7\%, $P<0.0001 ;$ OR 2.20). In the 'self-sampling' group, 320 used the self-sampling kit; for 44 of these women with positive HR-HPV test results, 40 had the recommended triage Pap smear. The ICER per extra screened woman was $77.8 €$ and $63.2 €$ for the 'recall' and 'self-sampling' groups, respectively, relative to the 'no intervention' group.

Conclusions: Offering an in-home, return-mail kit for vaginal self-sampling with a dry swab is more effective and cost-effective than a recall letter in increasing participation in cervical cancer screening.

Cervical cancer is the fourth most common cancer in women worldwide, with an estimated 528000 new cases and 266000 deaths in 2012 (Ferlay et al, 2013). Cervical cancer screening with Papanicolaou cytology (Pap smear) has resulted in a major reduction in both the incidence of the disease and related mortality (Lăără et al, 1987; Arbyn et al, 2009). However, screening coverage, estimated at $63 \%$ in developed countries and ranging from $>80 \%$ in Austria to $<50 \%$ in Ireland, remains often insufficient (Gakidou et al, 2008). In the region of Tours, in France, where the study took place, screening coverage is estimated at $62.7 \%$ (Duport et al, 2014). Common barriers to screening are accessibility to and acceptability of the pelvic examination needed for the cervical Pap smear (IARC, 2005). France currently has no organised national cervical cancer screening programme.

Persistent infection with high-risk human papillomavirus (HR-HPV) is a cause of invasive cervical cancer (Walboomers et al, 1999; Muñoz et al, 2003). HPV-based tests have been recently proposed as an alternative to cervical cancer screening in women 
aged $>30$ years and have been shown to be more sensitive than Pap smear in detecting cervical intraepithelial neoplasia (CIN) grade 2 or worse (CIN3 or cancer) (Arbyn et al, 2012). These new screening tests have led to vaginal self-sampling modes with lavages, brushes or swabs. HPV tests performed on vaginal selfsamples are accurate in detecting HPV cervical infection (Snijders et al, 2013). Moreover, tests with a dry swab are as accurate as those with a swab in liquid medium (Haguenoer et al, 2014).

Vaginal self-sampling has increased the participation in cervical cancer screening among unscreened women in various settings (Bais et al, 2007; Gök et al, 2010; Tamalet et al, 2010; Giorgi Rossi et al, 2011; Szarewski et al, 2011; Wikström et al, 2011; Virtanen et al, 2011a,b; Gök et al, 2012; Racey et al, 2013; Sancho-Garnier et al, 2013; Darlin et al, 2013b; Broberg et al, 2014). However, most studies of participation involved self-sampling devices requiring a liquid transport medium, which may be impractical for collection and transport and costly. Other studies involved dry self-sampling devices, whose accuracy as compared with clinician-collected samples has not been evaluated or has been evaluated only with a limited number of women. Finally, few of these studies provided cost-effectiveness data.

In this randomised controlled trial, we assessed the efficacy of a strategy based on vaginal self-sampling with an in-home, mailed, validated, self-sampling kit with a dry swab to increase participation in cervical cancer screening among unscreened women. We also assessed the cost-effectiveness of such a strategy.

\section{MATERIALS AND METHODS}

Design. We conducted a three-parallel-group randomised controlled trial. The study report follows the guidelines of the CONSORT statement extension for trials assessing non-pharmacological treatments and the template for intervention description and replication (TIDieR) checklist and guide (Boutron et al, 2008; Hoffmann et al, 2014).

Settings and participants. In 2010, in the absence of an organised national cervical cancer screening programme, the local Cancer Screening Department of the University Hospital of Tours established a regional cervical cancer screening programme. This department routinely collects health insurance reimbursement data and the major part (approximately 90\%) of Pap smear results from pathologists' files, which allows for identifying screened and unscreened women. Women identified as unscreened for $\geqslant 3$ years are invited by mail to visit their general practitioner (GP), gynaecologist or midwife to have a Pap smear. Nine months later, if they still have not had a Pap smear, they are sent a 'recall' reminder letter.

The present study took place in the region managed by the Cancer Screening Department of the University Hospital of Tours, where about 160000 women likely to be involved in a cervical cancer screening programme live. Eligible women were aged between 30 and 65 years and had not had a recent Pap smear despite an invitation 9 months previously. We excluded women who after the initial invitation declared that they (1) had a Pap smear in the past 3 years, (2) had a hysterectomy (including cervix), (3) had never had sexual intercourse or (4) had a cervical abnormality that was under exploration and/or treatment.

Interventions. We considered three groups defined as follows: (1) 'no intervention'; (2) 'recall', women received a letter to visit a GP, gynaecologist or midwife to have a Pap smear; and (3) 'selfsampling', women received a vaginal self-sampling kit.

For the 'self-sampling' group, we tailored the intervention as follows (Figure 1). A working group of epidemiologists, gynaecologists, virologists and statisticians held discussion sessions. The group chose to use a swab rather than a brush or lavage as a self-sampling device because of its high acceptability, low price and good sampling performance (Schmeink et al, 2011). In a previous study, we showed that HPV test results agreed among three formats: (1) a vaginal self-collected sample with a dry nylon flocked swab; (2) a vaginal self-collected sample with a nylon flocked swab in liquid medium; and (3) a clinician-collected cervical sample in liquid medium (Haguenoer et al, 2014). According to these findings, we selected the dry nylon flocked swab to avoid the use of a liquid medium.

The working group agreed on the content of the envelope sent to eligible women: (1) a letter inviting women to perform vaginal self-sampling, (2) a leaflet (designed in collaboration with a medical illustrator) explaining how to perform the vaginal selfsampling (Supplementary Information), (3) a nylon flocked swab in a non-breakable dry sterile tube (53080C, Copan, Brescia, Italy), (4) a resealable plastic bag, (5) an identification sheet, and (6) a prestamped, preaddressed envelope to return the self-sampling kit to a centralised laboratory (Virology Laboratory, Inter-Regional Health Institute, Tours, France) for HPV testing (see Laboratory testing below). If the HPV test result was uninterpretable, a new self-sampling kit was sent to the woman. If the second HPV test result was uninterpretable, women were advised by mail to have a Pap smear by health-care professional. Otherwise, if the test was negative for HR-HPV, the test result was mailed to the woman, and she was advised to have a Pap smear every 3 years. Finally, if the test was positive for HR-HPV, the test result was mailed to both the woman and her GP and the woman was advised to have a triage Pap smear as soon as possible (within 3 months). Three months after a positive HR-HPV test result, if the woman had not had a triage Pap smear, a reminder letter was sent. Three months later, if the woman had still not had a triage Pap smear, the woman was contacted by phone by the Cancer Screening Department staff. If the woman could not be contacted, a registered reminder letter with acknowledgement of receipt was sent, advising the woman to have a triage Pap smear as soon as possible.

For women with an abnormal screening or triage Pap smear test result, we collected follow-up results (HPV test, colposcopy, control Pap smear test, biopsy, etc.) according to Cancer Screening Department's usual procedures, in accordance with French Guidelines (French National Authority for Health, 2002): 4-9 months (depending of the Pap smear test result) after the abnormal Pap smear test result, a letter was sent (with prestamped, preaddressed return envelope) to the GP and/or the gynaecologist of the woman to collect follow-up results or to remind the need for follow-up if it had not been achieved. If no result could be collected, a letter was sent to the woman 1 year after the abnormal Pap smear test result to collect follow-up results or to remind the need for follow-up if it had not been achieved.

Randomisation sequence generation, allocation concealment, implementation. Among eligible women, 6000 were randomly selected (see sample size section): 3000 who were $30-49$ years old, and 3000 who were 50-65 years old. Then, within the two age strata, women were randomly assigned in equal proportions $(1: 1: 1)$ to one of the three groups, all at once. Both the random sampling and the randomisation were handled by an independent computer programmer who is in charge of the screening programme management software routinely used in the Cancer Screening Department (Zeus, OsiSanté, Thury Harcourt, France) and who was not further involved in the study. The allocation method was concealed to the study coordinator.

Ethics approval and blinding. The study protocol was approved by the local ethics committee who considered the study as a study on women's behaviour in response to a screening offer and therefore waived the requirement for informed consent. In both the 'recall' and 'self-sampling' groups, the letter sent indicated that participation was part of a research programme about screening, 
Home-mailed self-sampling kit in an envelope containing :

1) a recall letter inviting to perform a vaginal self-sampling

2) a leaflet designed in collaboration with a medical illustrator

3) a nylon flocked swab in a non-breakable dry sterile tube

4) a plastic resealable zipper bag

5) an identification sheet

6) a pre-stamped and pre-addressed envelope to return the self-sample to the laboratory
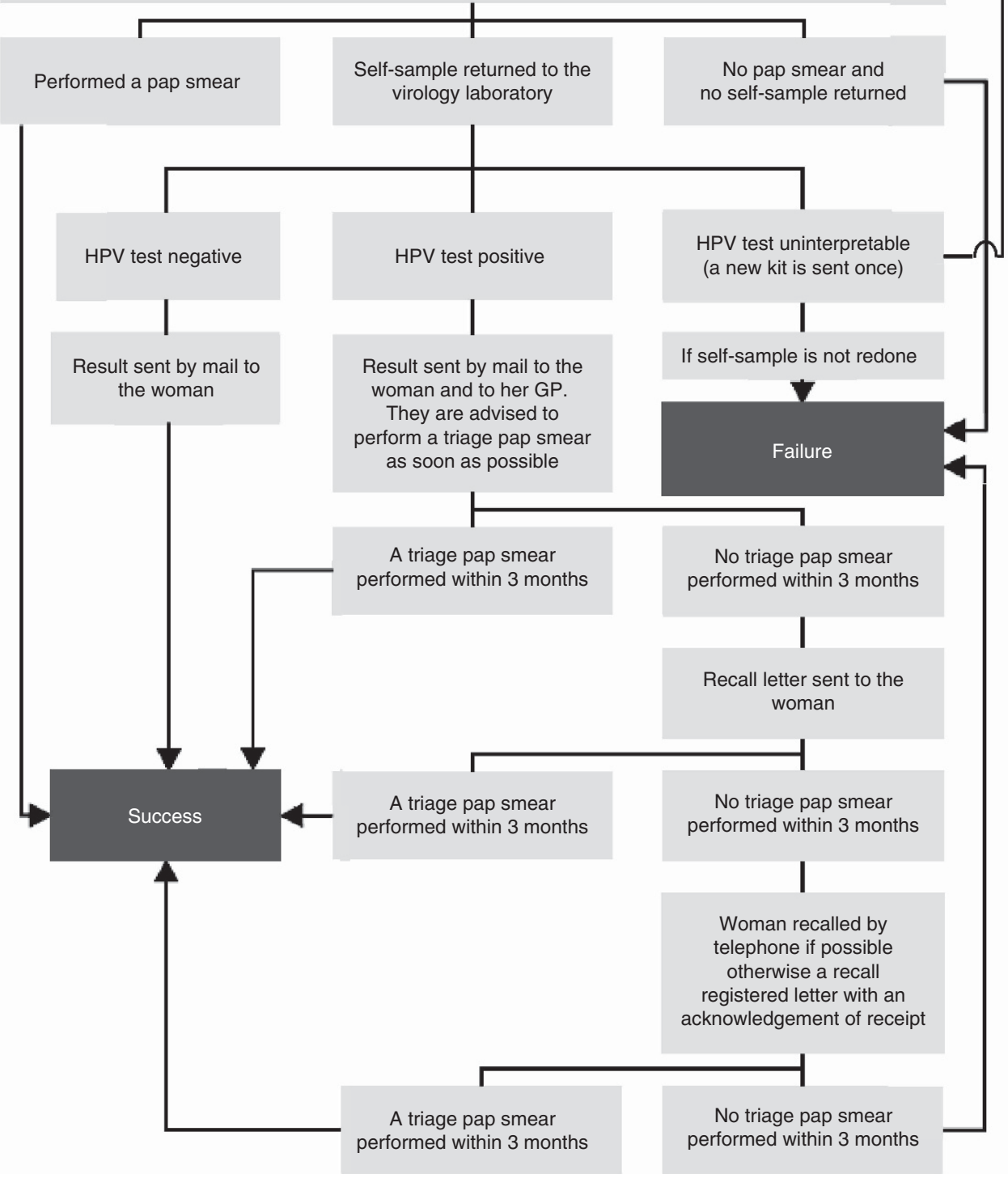

Figure 1. Procedure for the 'self-sampling' group. Abbreviation: HPV, human papillomavirus.

but women were not aware that there were included in a randomised trial. Finally, women in the 'no intervention' group received no information and therefore were unaware of the present study. In parallel, before randomisation, all GPs, gynaecologists and midwives working in the region where the study took place were informed by mail of the study's objectives. At the end of the study (April 2013), all included women received comprehensive information about the study hypothesis, study results and cervical cancer screening guidelines.

Laboratory testing. Pap smears were evaluated in cytology laboratories according to usual practices. PCR-based HPV tests were performed by well-trained virologists in a centralised laboratory (Virology Laboratory). Samples were first eluted in 3-ml buffer solution of phosphate-buffered saline. Then, samples were tested for HPV following the routine procedure previously described (Haguenoer et al, 2014) with HPV type-specific oligonucleotide probes bound to nitrocellulose strips (INNO-LiPA
HPV Genotyping Extra, Innogenetics, Ghent, Belgium) according to the manufacturer's protocol (Fontaine et al, 2007; Safaeian et al, 2007). The assay could identify $28 \mathrm{HPV}$ types, including $15 \mathrm{HR}$ HPV types (16, 18, 31, 33, 35, 39, 45, 51, 52, 56, 58, 59, 68, 73, 82), 3 probable high-risk HPV types (HR-HPV; 26, 53, 66), 7 low-risk HPV types (LR-HPV; 6, 11, 40, 43, 44, 54, 70) and 3 additional types with unknown risk $(69,71,74)$. The assay included a control line. A negative result for the control line indicated inadequate specimen collection or the presence of inhibitors in the DNA extract. In this case, the test result was considered uninterpretable.

HPV results were classified as positive for HR-HPV when at least one HR-HPV or probable HR-HPV type was detected and negative when no HPV or other HPV type was detected (low-risk $\mathrm{HPV}$, additional types, untypable).

Outcome measurement. Outcomes were assessed by the Cancer Screening Department from routinely collected data and HPV test results. The primary outcome was participation in complete 
cervical cancer screening within 9 months after randomisation. The secondary outcome was participation in complete screening within 12 months.

In the 'no intervention' and 'recall' groups, participation in complete screening was defined as having a Pap smear. In the 'selfsampling' group, participation in complete screening was defined as having a Pap smear or performing the self-sampling, eventually completed by a triage Pap smear performed by health-care professional in case of positive test results. Indeed, in case of negative results, the participation was considered complete, and, in case of positive results, the participation was considered complete with a triage Pap smear performed by health-care professional as recommended (Figures 1 and 2).

Finally, cytology (Pap smear) and histology (biopsy) results were extracted from routinely collected data from the Cancer Screening Department database. Pap smear results were classified by the 2001 Bethesda system (Solomon et al, 2002). Women who performed at least one follow-up test (control Pap smear test, HPV test, colposcopy) consistent with French Guidelines (French National Authority for Health, 2002) were considered to have began a follow-up procedure; those who performed a complete follow-up procedure consistent with the French Guidelines were considered

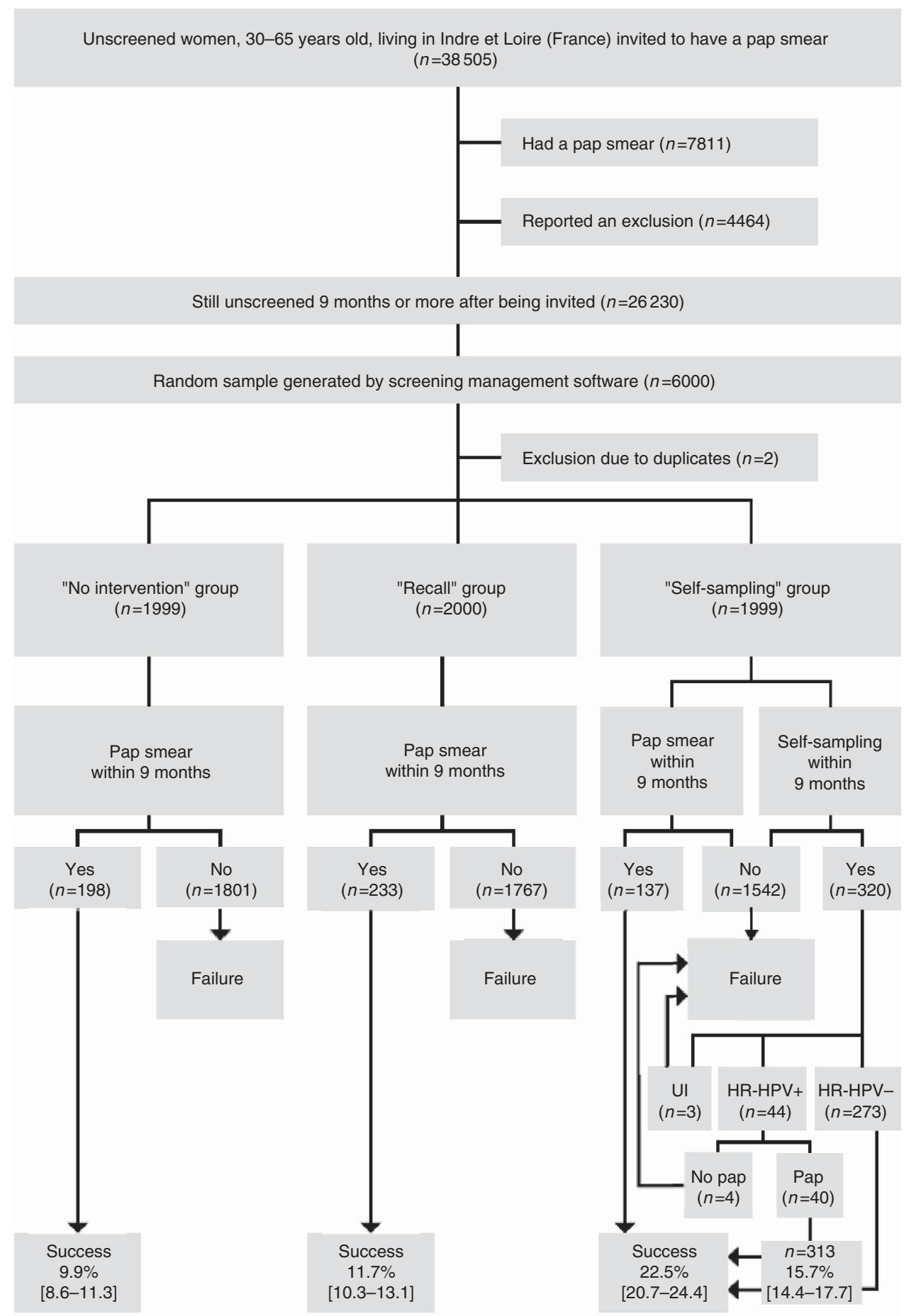

Figure 2. Study flow chart and results. Abbreviations: HR-HPV +, positive for high-risk HPV and/or probable high-risk HPV; HR-HPV - , negative for high-risk HPV and probable high-risk HPV; UI, uninterpretable HPV test result. 95\% confidence intervals are presented in brackets. 
to have a full follow-up. Histology results were classified as normal, CIN1, CIN2, CIN3 or cancer.

Sample size determination. From comparable published data (Bais et al, 2007; Szarewski et al, 2011) and based on knowledge of the local situation in the screening programme, we assumed a $30 \%$ participation rate in the 'no intervention' group. We hypothesised a $5 \%$ increase in participation in the 'recall' group, and a further $5 \%$ increase in the 'self-sampling' group. Considering that pairwise comparisons would be performed, we considered a two-sided alpha level of 0.0167 and a power of $80 \%$, for 1953 women needed in each group. Finally, 6000 women were included.

Statistical analysis. Analyses followed the principle of intent-toscreen. Participation rates were reported with their 95\% confidence intervals ( $95 \%$ CIs). Odds ratios (ORs) were estimated by logistic models. Subgroup analyses were performed considering interaction terms between age and intervention groups. The 'no intervention' group was considered as the reference for comparisons. Data were analysed by the use of SAS v9.2 (SAS Inc., Cary, NC, USA).

Medico-economic evaluation. A cost-effectiveness analysis was performed according to the guidelines of the French National Authority for Health (French National Authority for Health, 2012). The societal point of view was adopted to consider costs supported by health insurance, the Cancer Screening Department and women. Only direct costs were taken into account (Table 4).

A cost per screened woman was calculated for each group. Interventions were ranked in terms of costs from the cheapest to the most expensive. If an intervention was more expensive and less effective than the previous one, then it was said to be strongly dominated and was excluded from further analysis. Incremental cost-effectiveness ratios (ICERs) per extra screened woman were calculated for each intervention by dividing the between-strategy cost difference by the between-strategy number of screened women. ICERs for each intervention were compared with the next most-expensive, non-dominated option. If the ICER for an intervention was higher than that for the next most-effective intervention, it was ruled out by extended dominance. ICERs were then recalculated for the remaining interventions. A sensitivity analysis was conducted to account for the uncertainty of efficacy results and cost trends.

\section{RESULTS}

Participants. Between November 2010 and April 2011, 38505 women in the study area were identified as unscreened for cervical cancer. They were invited to visit their GPs, gynaecologist or midwife to have a Pap smear: 7811 had a Pap smear and 4464 reported exclusion criteria. On March 2012, among the 26230 remaining women (median age 51.1 years, range 30.0-65.0), 6000 women (3000, 30-49 years; and 3000, 50-65 years) were randomly selected and randomised to one of the three groups. Because of duplicate selection, 2 women were further excluded, which led to a final sample of 5998 women.

Study conduct. Because of address errors, recall letters could not be delivered to 156 women (7.8\%), nor 164 (8.2\%) self-sampling kits. In the 'self-sampling' group, four women had an uninterpretable HPV test result; two performed a second self-sampling, but one test result was again uninterpretable. The two other women did not perform a second self-sampling.

Participation in complete cervical cancer screening. At 9 months after randomisation, the participation in complete cervical cancer screening was significantly higher for the 'self-sampling' than for the 'no intervention' group (22.5\% vs $9.9 \%$; OR 2.64, $95 \%$ CI $(2.21 ; 3.17)$ and the 'recall' group $(11.7 \%$, OR $2.20,95 \%$ CI $(1.85 ; 2.62)$, with no difference between the 'recall' and 'no intervention' groups (OR $1.20,95 \%$ CI $(0.98 ; 1.47))$. In the 'selfsampling' group, of the 320 women $(16.0 \%, 95 \%$ CI $(14.4 ; 17.7))$ who returned a self-sample, $313(15.7 \%, 95 \%$ CI $(14.1 ; 17.3))$ were considered as screened by self-sampling (see 'Test results and follow-up' section), whereas 137 women $(6.9 \%$, 95\% CI $(5.8 ; 8.1)$ ) directly performed a screening Pap smear (Table 1 and Figure 2).

For the two age subgroups, results were qualitatively the same, except for women aged 50-65 years, the participation rate was higher for the 'recall' than for the 'no intervention' group.

Results were stable at 12 months after randomisation (Table 2). Between months 9 and 12 after randomisation, 3 women performed self-sampling (negative for HR-HPV) and 50 had a Pap smear in the 'no intervention' group, 43 in the 'recall' group and 35 in the 'self-sampling' group.

Test results and follow-up. In the 'self-sampling' group, 320 women performed self-sampling within 9 months and 317 test results were interpretable, with 44 samples $(13.9 \%$, 95\% CI

Table 1. Participation in complete cervical cancer screening within 9 months after randomisation, by intervention and age groups

\begin{tabular}{|c|c|c|c|c|c|}
\hline \multirow[b]{2}{*}{ Age group } & \multirow[b]{2}{*}{ Intervention group (no. of women) } & \multicolumn{4}{|c|}{ Participation } \\
\hline & & $\begin{array}{c}\text { Pap smear, n } \\
(\%)\end{array}$ & $\begin{array}{c}\text { Self-sampling, } n \\
(\%)\end{array}$ & Total, $n(\%)$ & Odds ratio $(95 \% \mathrm{Cl})$ \\
\hline Total & $\begin{array}{l}\text { No intervention group }(n=1999) \\
\text { Recall group }(n=2000) \\
\text { Self-sampling group }(n=1999)\end{array}$ & $\begin{array}{l}198(9.9 \%) \\
233(11.7 \%) \\
137(6.9 \%)\end{array}$ & $\begin{array}{c}- \\
- \\
313(15.7 \%)^{\mathrm{a}}\end{array}$ & $\begin{array}{l}198(9.9 \%) \\
233(11.7 \%) \\
450(22.5 \%)\end{array}$ & $\begin{array}{c}1.00 \\
1.20(0.98 ; 1.47) \\
2.64(2.21 ; 3.17)\end{array}$ \\
\hline \multicolumn{6}{|l|}{ Subgroup analysis ${ }^{b}$} \\
\hline Women aged $30-49$ years & $\begin{array}{l}\text { No intervention group }(n=1000) \\
\text { Recall group }(n=1000) \\
\text { Self-sampling group }(n=999)\end{array}$ & $\begin{array}{c}104(10.4 \%) \\
94(9.4 \%) \\
73(7.3 \%)\end{array}$ & $\begin{array}{c}- \\
- \\
147(14.7 \%)\end{array}$ & $\begin{array}{c}104(10.4 \%) \\
94(9.4 \%) \\
220(22.0 \%)\end{array}$ & $\begin{array}{c}1.00 \\
0.89(0.67 ; 1.20) \\
2.43(1.89 ; 3.13)\end{array}$ \\
\hline Women aged $50-65$ years & $\begin{array}{l}\text { No intervention group }(n=999) \\
\text { Recall group }(n=1000) \\
\text { Self-sampling group }(n=1000)\end{array}$ & $\begin{array}{c}94(9.4 \%) \\
139(13.9 \%) \\
64(6.4 \%)\end{array}$ & $\begin{array}{c}- \\
- \\
166(16.6 \%)\end{array}$ & $\begin{array}{c}94(9.4 \%) \\
139(13.9 \%) \\
230(23.0 \%)\end{array}$ & $\begin{array}{c}1.00 \\
1.55(1.18 ; 2.05) \\
2.88(2.22 ; 3.72)\end{array}$ \\
\hline \multicolumn{6}{|c|}{$\begin{array}{l}\text { Abbreviation: } \mathrm{Cl}=\text { confidence interval. } \\
\text { aWithin } 9 \text { months after randomisation, } 320 \text { women performed vaginal self-sampling, but only } 313 \text { were considered as having participated in complete screening action because } 4 \text { did not hav } \\
\text { the recommended Pap smear and } 3 \text { had an uninterpretable HPV test result. } \\
\text { b }_{\text {Interaction test, } P=0.0193 \text {. }}\end{array}$} \\
\hline
\end{tabular}


$(10.3 ; 18.2)$ ) positive for HR-HPV (Figure 2); 40 of these women had the recommended triage Pap smear (90.9\%, 95\% CI (78.3; 97.5)).

Among women who participated in complete screening at 12 months after randomisation, a Pap smear test result was available for 653 out of 736 (88.7\%): 218 out of 248 (87.9\%) in the 'no intervention' group, 250 out of $276(90.6 \%)$ in the 'recall' group, and 185 out of $212(87.3 \%)$ in the 'self-sampling' group. For the remaining women, only the health insurance reimbursement date of the Pap smear test was known. Among 653 Pap smear test results, $32(4.9 \%)$ were abnormal with 26 on a screening Pap smear test and 6 on a triage Pap smear test after positive HR-HPV result on the vaginal self-sampling; 8 out of 218 (3.7\%) in the 'no intervention' group, 11 out of $250(4.4 \%)$ in the 'recall' group and 13 out of $185(7.0 \%)$ in the 'self-sampling' group, (7 out of 150 among women who performed a screening Pap smear and 6 out of 35 among triage Pap smear) (Table 3).

Among 32 women with abnormal screening or triage Pap smear test result, $27(84.4 \%$, 95\% CI $(67.2 ; 94.7))$ began a follow-up procedure (i.e., had at least one follow-up test) of which 14 had a full follow-up (complete and consistent with guidelines): 7 out of 8 began a follow-up ( 2 full follow-ups) in the 'no intervention' group, 9 out of 11 began a follow-up (5 full follow-ups) in the 'recall' group, and 11 out of 13 began a follow-up ( 7 full follow-ups) in the 'self-sampling' group. In this latter group, 5 out of 7 began a follow-up ( 3 full follow-ups) in women who directly performed a screening Pap smear, and 6 out of 6 began a follow-up (4 full follow-ups) in women who had an abnormal triage Pap smear test result after a positive HR-HPV test result on a self-sample. Among 26 women with abnormal screening Pap smear test result (excluding the 6 women with an abnormal triage Pap smear test result), 21 (80.8\%, 95\% CI $(60.6 ; 93.4))$ began a follow-up procedure of which 10 had a full follow-up.

Finally, among women who participated in complete screening at 12 months after randomisation, 7 had CIN2 grade cancer or worse: 1 CIN3 in the 'no intervention' group and 1 CIN3 in the 'recall' group; and 3 CIN3 in the 'self-sampling' group among HRHPV-positive women and 2 CIN2 in the 'self-sampling' group

Table 2. Participation in a complete cervical cancer screening within 12 months after randomisation, by intervention and age groups

\begin{tabular}{|c|c|c|c|c|c|}
\hline \multirow[b]{2}{*}{ Age group } & \multirow[b]{2}{*}{ Intervention group (no. of women) } & \multicolumn{4}{|c|}{ Participation } \\
\hline & & $\begin{array}{c}\text { Pap smear, } n \\
(\%)\end{array}$ & $\begin{array}{c}\text { Self-sampling, } n \\
(\%)\end{array}$ & Total, $n$ (\%) & Odds ratio $(95 \% \mathrm{Cl})$ \\
\hline Total & $\begin{array}{l}\text { No intervention group }(n=1999) \\
\text { Recall group }(n=2000) \\
\text { Self-sampling group }(n=1999)\end{array}$ & $\begin{array}{l}248(12.4 \%) \\
276(13.8 \%) \\
172(8.6 \%)\end{array}$ & $\begin{array}{c}- \\
- \\
316(15.8 \%)^{a}\end{array}$ & $\begin{array}{l}248(12.4 \%) \\
276(13.8 \%) \\
488(24.4 \%)\end{array}$ & $\begin{array}{c}1.00 \\
1.13(0.94 ; 1.36) \\
2.28(1.93 ; 2.70)\end{array}$ \\
\hline \multicolumn{6}{|l|}{ Subgroup analysis ${ }^{b}$} \\
\hline Women aged $30-49$ years & $\begin{array}{l}\text { No intervention group }(n=1000) \\
\text { Recall group }(n=1000) \\
\text { Self-sampling group }(n=999)\end{array}$ & $\begin{array}{c}137(13.7 \%) \\
112(11.2 \%) \\
92(9.2 \%)\end{array}$ & $\begin{array}{c}- \\
- \\
148(14.8 \%)\end{array}$ & $\begin{array}{l}137(13.7 \%) \\
112(11.2 \%) \\
240(24.0 \%)\end{array}$ & $\begin{array}{c}1.00 \\
0.79(0.61 ; 1.04) \\
1.99(1.58 ; 2.51)\end{array}$ \\
\hline Women aged $50-65$ years & $\begin{array}{l}\text { No intervention group }(n=999) \\
\text { Recall group }(n=1000) \\
\text { Self-sampling group }(n=1000)\end{array}$ & $\begin{array}{c}111(11.1 \%) \\
164(16.4 \%) \\
80(8.0 \%)\end{array}$ & $\begin{array}{c}- \\
- \\
168(16.8 \%)\end{array}$ & $\begin{array}{l}111(11.1 \%) \\
164(16.4 \%) \\
248(24.8 \%)\end{array}$ & $\begin{array}{c}1.00 \\
1.57(1.21 ; 2.03) \\
2.64(2.07 ; 3.37)\end{array}$ \\
\hline \multicolumn{6}{|c|}{$\begin{array}{l}\text { Abbreviation: } \mathrm{Cl}=\text { confidence interval. } \\
\text { aWithin } 12 \text { months after randomisation, } 324 \text { women performed vaginal self-sampling, but only } 316 \text { were considered as having participated in complete cervical cancer screening because } 4 \text { did } \\
\text { not have the recommended Pap smear and } 3 \text { had an uninterpretable HPV test result. } \\
\text { b Interaction test, } P=0.0014 \text {. }\end{array}$} \\
\hline
\end{tabular}

Table 3. Pap smear results by intervention group and the type of participation among women who participated in complete cervical cancer screening within 12 months after randomisation

\begin{tabular}{|c|c|c|c|c|c|}
\hline \multirow[b]{3}{*}{ Pap smear result } & \multicolumn{5}{|c|}{ Intervention group } \\
\hline & \multirow[b]{2}{*}{$\begin{array}{l}\text { No intervention } \\
(N=248)\end{array}$} & \multirow[b]{2}{*}{ Recall $(N=276)$} & \multicolumn{3}{|c|}{ Self-sampling } \\
\hline & & & $\begin{array}{l}\text { Screening Pap smear } \\
(N=172)\end{array}$ & $\begin{array}{l}\text { Triage Pap smear } \\
(N=40)^{\mathrm{a}}\end{array}$ & Total $(N=212)$ \\
\hline Unknown result ${ }^{\mathrm{b}}$ & $30(12.1 \%)$ & $26(9.4 \%)$ & $22(12.8 \%)$ & $5(12.5 \%)$ & $27(12.7 \%)$ \\
\hline Known result ${ }^{c}$ & $218(87.9 \%)$ & $250(90.6 \%)$ & $150(87.2 \%)$ & $35(87.5 \%)$ & $185(87.3 \%)$ \\
\hline Normal & $210(84.7 \%)$ & 239 (86.6\%) & $143(83.1 \%)$ & $29(72.5 \%)$ & $172(81.1 \%)$ \\
\hline Abnormal & $8(3.2 \%)$ & $11(4.0 \%)$ & $7(4.1 \%)$ & $6(15.0 \%)$ & $13(6.1 \%)$ \\
\hline ASC-US & $3(1.2 \%)$ & $8(2.9 \%)$ & $3(1.7 \%)$ & $2(5.0 \%)$ & $5(2.4 \%)$ \\
\hline ASC-H & 1 (0.4\%) & - & $1(0.6 \%)$ & - & $1(0.5 \%)$ \\
\hline LSIL & $3(1.2 \%)$ & $2(0.7 \%)$ & $1(0.6 \%)$ & $1(2.5 \%)$ & $2(0.9 \%)$ \\
\hline $\mathrm{HSIL}$ & $1(0.4 \%)$ & $1(0.4 \%)$ & $1(0.6 \%)$ & $3(7.5 \%)$ & $4(1.9 \%)$ \\
\hline AGC & - & - & $1(0.6 \%)$ & - & $1(0.5 \%)$ \\
\hline \multicolumn{6}{|c|}{ 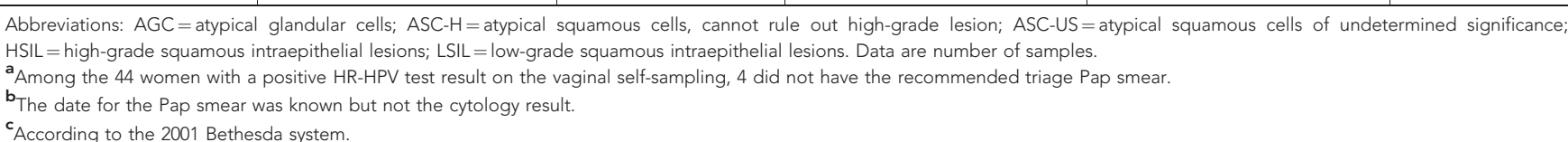 } \\
\hline
\end{tabular}


among women who had a Pap smear. The CIN2 + detection rate among included women was $0.50 \%$ o $(95 \%$ CI $(0.01 ; 2.78))$ in the 'no intervention' and 'recall' groups and $2.5 \%$ ( $95 \% \mathrm{CI}(0.81 ; 5.83))$ in the 'self-sampling' group.

Cost-effectiveness analysis. The total cost was higher for the 'selfsampling' than for the 'recall' group (26 855.95€ vs $13651.27 €)$ and the 'no intervention' group (10929.62€). No strategy strongly dominated (more expensive and less effective) (Table 4). The ICER per extra screened woman was $77.8 €$ in the 'Recall' group (ruled out by extended dominance) and $63.2 €$ in the 'self-sampling' group relative to the 'no intervention' group. Sensitivity analysis revealed that ICERs were related to participation rates, screening test costs (Pap smear analysis and HPV test), medical consultation extra fees, postal fees and self-sampling device cost.

\section{DISCUSSION}

In a large sample of 5998 women, we showed that an in-home, mailed, vaginal self-sampling kit with a dry swab increased participation in a cervical cancer screening programme among previous non-attendees. These results apply to women both 30-49 and 50-65 years old. Recall letters were not more effective than no intervention, particularly among younger women. Among women with a positive HR-HPV test result, 90.9\% had the recommended Pap smear by a health-care professional. The cost-effectiveness analysis showed that the additional costs of the self-sampling strategy were offset by the substantial increase in participation, if using an inexpensive self-sampling device.

Table 4. Resources required per screened women by intervention group

\begin{tabular}{|c|c|c|c|c|c|c|c|}
\hline & & \multicolumn{2}{|c|}{ No intervention $(n=1999)$} & \multicolumn{2}{|c|}{ Recall $(n=2000)$} & \multicolumn{2}{|c|}{ Self-sampling $(n=1999)$} \\
\hline & Unit costs $(€)$ & Units & Cost $(€)$ & Units & Cost $(€)$ & Units & Cost $(€)$ \\
\hline $\begin{array}{l}\text { Identification of screened and unscreened } \\
\text { women }^{\text {a }}\end{array}$ & & & 398.00 & & 398.00 & & 398.00 \\
\hline \multicolumn{8}{|l|}{ Intervention } \\
\hline $\begin{array}{l}\text { Recall letter }^{b} \\
\text { Self-sampling kit }\end{array}$ & $\begin{array}{l}0.43 \\
2.30\end{array}$ & & & 2000 & 860.00 & 1999 & 4597.70 \\
\hline \multicolumn{8}{|l|}{ Screening } \\
\hline $\begin{array}{l}\text { Pap smear }{ }^{\mathrm{d}} \\
\text { Self-sampling return and HPV test }\end{array}$ & $\begin{array}{l}53.19 \\
38.39\end{array}$ & 198 & 10531.62 & 233 & 12393.27 & $\begin{array}{l}137 \\
320\end{array}$ & $\begin{array}{c}7287.03 \\
12284.80\end{array}$ \\
\hline \multicolumn{8}{|l|}{ Uninterpretable HPV test result } \\
\hline $\begin{array}{l}\text { Self-sampling kit }{ }^{\mathrm{c}} \\
\text { Self-sampling return and HPV test }\end{array}$ & $\begin{array}{r}2.30 \\
38.39\end{array}$ & & & & & $\begin{array}{l}4 \\
2\end{array}$ & $\begin{array}{c}9.20 \\
76.78\end{array}$ \\
\hline \multicolumn{8}{|l|}{ Follow-up for HR-HPV +} \\
\hline $\begin{array}{l}\text { Pap smear }^{\mathrm{d}} \\
\text { Reminder letter within } 3 \text { months } \\
\text { Reminder phone call within } 6 \text { months }^{\mathrm{g}}\end{array}$ & $\begin{array}{r}53.19 \\
0.62 \\
5.00\end{array}$ & & & & & $\begin{array}{l}40 \\
32 \\
11\end{array}$ & $\begin{array}{c}2127.60 \\
19.84 \\
55.00\end{array}$ \\
\hline Total cost & & & 10929.62 & & 13651.27 & & 26855.95 \\
\hline No. of screened women ${ }^{h}$ & & 198 & & 233 & & 450 & \\
\hline Cost per screened woman $(95 \% \mathrm{Cl})^{\mathrm{i}}$ & & & $\begin{array}{c}55.2 € \\
(54.9 ; 55.4)\end{array}$ & & $\begin{array}{c}58.6 € \\
(58.1 ; 59.2)\end{array}$ & & $\begin{array}{c}59.7 € \\
(58.6 ; 62.2)\end{array}$ \\
\hline ICER per extra screened woman ${ }^{j}$ & & & & & $77.8 €^{\mathrm{k}}$ & & $63.2 €$ \\
\hline \multicolumn{8}{|c|}{ Sensitivity analysis (ICER per extra screened woman') } \\
\hline $\begin{array}{l}\text { Efficacy parameters } \\
\text { Participation rate (worst assumption } \\
\text { for the self-sampling group) }\end{array}$ & & & & & $62.7 €$ & & $63.1 \epsilon^{k}$ \\
\hline $\begin{array}{l}\text { Screening costs } \\
\text { No extra fees for medical consultation } \\
\text { HPV test }=\text { cytology analysis }=25 € \\
\text { HPV test }=25 €\end{array}$ & & & & & $\begin{array}{l}68.8 €^{k} \\
87.4 €^{k} \\
77.8 €^{k}\end{array}$ & & $\begin{array}{l}63.9 € \\
47.8 € \\
48.6 €\end{array}$ \\
\hline $\begin{array}{l}\text { Intervention costs } \\
\text { Postal fees }+20 \% \\
\text { Postal fees }-20 \% \\
\text { Self-sampling kit } 5.00 € \text { (vs 2.30€) } \\
\end{array}$ & & & & & $\begin{array}{l}82.9 €^{\mathrm{k}} \\
77.2 €^{\mathrm{k}} \\
77.8 €\end{array}$ & & $\begin{array}{l}66.9 € \\
59.6 € \\
84.6 €^{\mathrm{k}}\end{array}$ \\
\hline 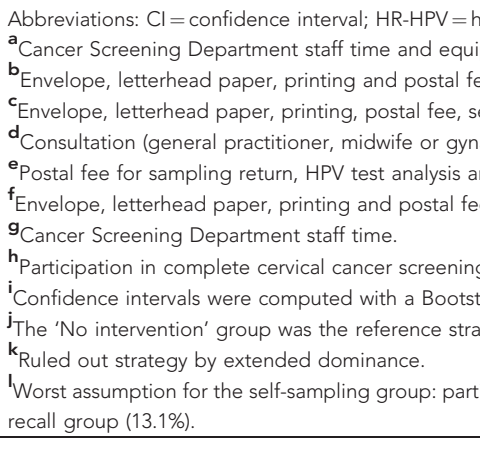 & $\begin{array}{l}\text { sk human papilloma } \\
\text { it. } \\
\text { mpling device, leafle } \\
\text { ogist) including pot } \\
\text { nding the result. } \\
\text { in } 9 \text { months. } \\
\text { nethod. } \\
\text { ion rate lower limit c }\end{array}$ & $\begin{array}{l}\text { avirus; ICER = in } \\
\text { et, resealable zi } \\
\text { ential extra fees }\end{array}$ & $\begin{array}{l}\text { tal cost-effective } \\
\text { ag, identification } \\
\text { gy analysis and }\end{array}$ & $\begin{array}{l}\text { ratio. } \\
\text { t and retu } \\
\text { er Screen }\end{array}$ & $\begin{array}{l}\text { velope. } \\
\text { epartment staf }\end{array}$ & $(20.7 \%) a$ & rimit for the \\
\hline
\end{tabular}


Table 5. Randomised controlled trials comparing the efficacy of a self-sampling kit and recall letters in participation in cervical cancer screening

\begin{tabular}{|c|c|c|c|c|c|c|c|c|}
\hline \multirow[b]{2}{*}{ Author } & \multirow[b]{2}{*}{$\begin{array}{l}\text { Setting (no. of } \\
\text { participants) }\end{array}$} & \multirow[b]{2}{*}{ Self-sampling and } & \multirow[b]{2}{*}{$\begin{array}{l}\text { Transport } \\
\text { method }\end{array}$} & \multirow[b]{2}{*}{$\begin{array}{l}\text { HPV test } \\
\text { method }\end{array}$} & \multirow[b]{2}{*}{$\begin{array}{c}\text { Cost- } \\
\text { effective- } \\
\text { ness } \\
\text { analysis }\end{array}$} & \multicolumn{3}{|c|}{ Participation } \\
\hline & & & & & & $\begin{array}{c}\text { Self- } \\
\text { sampling }\end{array}$ & $\begin{array}{l}\text { Recall } \\
\text { letter }\end{array}$ & $P$-value ${ }^{a}$ \\
\hline Bais et al, 2007 & Netherlands (2830) & Brush & Liquid & PCR-based & Yes & $34.2 \%$ & $17.6 \%$ & $<0.001$ \\
\hline Gök et al, 2010 & Netherlands (28 073) & Lavage & Liquid & Hybrid capture & No & $27.5 \%$ & $16.6 \%$ & $<0.001$ \\
\hline Giorgi Rossi et al, 2011 & Italy (2480) & Lavage & Liquid & Hybrid capture & No & $19.6 \%$ & $13.9 \%$ & 0.007 \\
\hline Szarewski et al, 2011 & Great Britain (3000) & Cotton swab & Liquid & Hybrid capture & No & $10.2 \%$ & $4.5 \%$ & $<0.0001$ \\
\hline Virtanen et al, 2011a & Finland (4160) & Lavage & Liquid & Hybrid capture & No & $29.8 \%$ & $26.2 \%$ & 0.021 \\
\hline Wikström et al, 2011 & Sweden (4060) & Plastic wand & Dry $^{b}$ & Hybrid capture & No & $39.0 \%$ & $9.0 \%$ & $<0.001$ \\
\hline Virtanen et al, 2011b & Finland (8699) & Lavage & Liquid & Hybrid capture & No & $31.5 \%$ & $25.9 \%$ & $<0.0001$ \\
\hline Gök et al, 2012 & Netherland (26 409) & Brush & Liquid & Hybrid capture & No & $30.8 \%$ & $6.5 \%$ & $<0.001$ \\
\hline Tamalet et al, 2010 & France (9334) & Nylon flocked swab & Liquid & PCR-based & No & $25.1 \%$ & $7.3 \%$ & $<0.001$ \\
\hline Darlin et al, 2013b & Sweden (1500) & Cotton swab & Dry $^{c}$ & PCR-based & No & $14.7 \%$ & $4.2 \%$ & $<0.0001$ \\
\hline Sancho-Garnier et al, 2013 & France (18730) & Nylon flocked swab & Liquid & PCR-based & No & $18.3 \%$ & $2.0 \%$ & $<0.001$ \\
\hline Broberg et al, 2014 & Sweden (8800) & Plastic wand & Dry $^{b}$ & Hybrid capture & Yes & $24.5 \%$ & $10.6 \%$ & $<0.0001$ \\
\hline $\begin{array}{l}\text { Haguenoer et al (present } \\
\text { study) }\end{array}$ & France (6000) & Nylon flocked swab & Dry $^{d}$ & PCR-based & Yes & $22.5 \%$ & $11.7 \%$ & $<0.0001$ \\
\hline \multicolumn{9}{|c|}{ 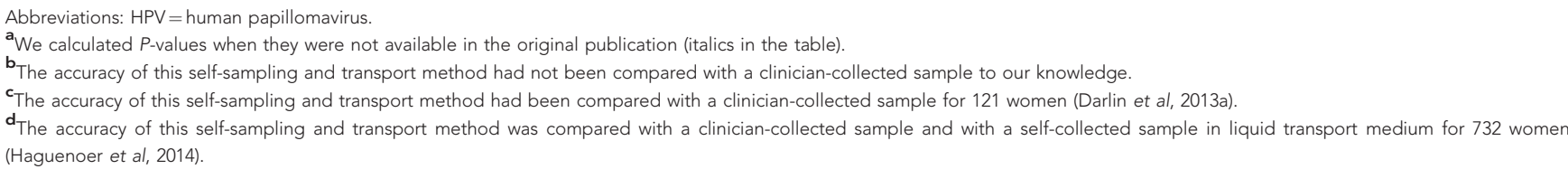 } \\
\hline
\end{tabular}

Several studies assessed the effect on screening participation of in-home, mailed, vaginal self-sampling kits as compared with recall letters (Table 5; Bais et al, 2007; Gök et al, 2010; Tamalet et al, 2010; Giorgi Rossi et al, 2011; Szarewski et al, 2011; Wikström et al, 2011; Virtanen et al, 2011a,b; Gök et al, 2012; Sancho-Garnier et al, 2013; Darlin et al, 2013b; Broberg et al, 2014). Despite the large heterogeneity in participation rates among studies, the selfsampling strategy increased participation in cervical cancer screening, whatever the study, that is, whatever the setting and the device (liquid transport or dry). Therefore, our findings agree with previously reported results. We further showed that a recall letter had no effect on participation as compared with no intervention. Extrapolating the findings of our study to the whole cervical cancer screening programme in the region of Tours where the study took place, an in-home mailed vaginal self-sampling strategy could increase the total estimated screening coverage from $62.7 \%$ to $67.3 \%$. Moreover, to our knowledge, our study was the first to provide cost-effectiveness data for vaginal self-sampling increasing participation among unscreened women with a validated dry self-sampling device and a PCR-based HPV test.

From a practical viewpoint, neither the self-sampling device (brush, swab or lavage) (Arbyn et al, 2014) nor the transport method (liquid or dry) (Cerigo et al, 2012; Van Baars et al, 2012; Eperon et al, 2013; Darlin et al, 2013a; Haguenoer et al, 2014) seemed to significantly affect the sensitivity and specificity of the self-sampling test and the efficacy in increasing participation. Therefore, when defining a screening programme, logistical and cost issues should be the major criteria to select a self-sampling device and transport method for a screening programme (Gravitt and Rositch, 2014), and dry devices could meet those criteria.

In a recent meta-analysis of the accuracy of HPV testing with clinician- $v$ s self-collected samples. Arbyn et al (2014) suggested that, given their high sensitivity, PCR-based HPV testing is preferred to hybrid capture methods for self-samples. For selfsampling, use of a test with a high analytic sensitivity seems to be needed to ensure similar accuracy between clinician- and selfcollected samples, probably because of the lower viral load in the vagina than the cervix (Belinson et al, 2010; Gravitt and Rositch, 2014; Zhang et al, 2014).

From a medico-economic viewpoint, our data show that despite a higher total cost of self-sampling, the strategy could be costeffective as compared with a recall letter when considering the cost per extra screened woman. This finding was linked in particular to the large difference in participation with the two strategies and the low cost of the self-sampling device we used. Further exploration is needed of the cost per quality-adjusted life years of a self-sampling strategy based on an inexpensive device; such data could be obtained by using our data in an existing medico-economic model (Goldie et al, 2004).

In conclusion, policy makers could consider vaginal selfsampling as an alternative to recall letters to increase participation in organised cervical cancer screening programmes. However, careful attention should be paid to defining the women to target, the device to use and to each logistical detail to optimise participation, efficacy and cost-effectiveness. Therefore, a wellorganised cervical cancer screening programme (Arbyn et al, 2010) should be an essential precondition to implement an effective and efficient self-sampling strategy.

\section{ACKNOWLEDGEMENTS}

We thank all women who participated in the study. We thank Aurélie Avargues for data monitoring, and Dr Philippe Bertrand for ethical and methodological advice. The French National Cancer Institute (INCa) provided financial support for the study (no. INCa_0874). Nylon flocked swabs were provided at no charge by Copan, Brescia, Italy. INCa conducted an external scientific review of the proposal before approving it. INCa and Copan were not 
involved in the design and conduct of the study nor in the collection, management, analysis and interpretation of the data. The decision to publish was made by the study investigators.

\section{CONFLICT OF INTEREST}

Dr Haguenoer received grant support from the French National Cancer Institute and French League Against Cancer; received support from Innogenetics and Sanofi Pasteur MSD for travel expenses to an HPV congress; and participated without compensation in meetings on cervical cancer prevention organised by Sanofi Pasteur MSD and GlaxoSmithKline. Dr Sengchanh and Dr GaudyGraffin received support from Innogenetics and Sanofi Pasteur MSD for travel expenses to an HPV congress and participated without compensation in meetings on cervical cancer prevention organised by Sanofi Pasteur MSD and GlaxoSmithKline. Dr Marret was invited to an international congress on HPV and participated without compensation in meetings on cervical cancer prevention organised by Sanofi Pasteur MSD and GlaxoSmithKline. The remaining co-authors report no financial disclosures. We did not use any writing assistance but used English language editing services.

\section{AUTHOR CONTRIBUTIONS}

Haguenoer had full access to all of the data in the study and takes responsibility for the integrity of the data and the accuracy of the data analysis. Study concept and design: Haguenoer, Giraudeau, Marret and Goudeau. Acquisition of data: Cancer Screening Department, Virology Laboratory. Analysis and interpretation of data: Haguenoer, Sengchanh, Boyard, Fontenay, Pigneaux de Laroche and Giraudeau. Drafting of the manuscript: Haguenoer and Giraudeau. Critical revision of the manuscript for important intellectual content: Haguenoer, Sengchanh, Gaudy Graffin, Boyard, Fontenay, Marret, Goudeau, Pigneaux de Laroche and Giraudeau. Statistical analysis: Haguenoer and Giraudeau. Obtained funding: Haguenoer, Giraudeau, Marret and Goudeau. Administrative, technical or material support: Haguenoer, Sengchanh, Boyard, Fontenay, Pigneaux de Laroche and Giraudeau. Virology analysis: Pigneaux de Laroche. Cost-effectiveness analysis: Fontenay and Rusch. Study supervision: Haguenoer, Giraudeau, Marret and Goudeau.

\section{TRANSPARENCY DECLARATION}

The lead author affirms that the manuscript is an honest, accurate and transparent account of the study being reported; that no important aspects of the study have been omitted; and that any discrepancies from the study as planned have been explained.

\section{DATA SHARING}

Data sets are available from the corresponding author.

\section{REFERENCES}

Arbyn M, Anttila A, Jordan J, Ronco G, Schenck U, Segnan N, Wiener H, Herbert A, von Karsa L (2010) European Guidelines for Quality Assurance in Cervical Cancer Screening. Second edition-summary document. Ann Oncol 21: 448-458.
Arbyn M, Raifu AO, Weiderpass E, Bray F, Anttila A (2009) Trends of cervical cancer mortality in the member states of the European Union. Eur $J$ Cancer 45: 2640-2648.

Arbyn M, Ronco G, Anttila A, CJLM Meijer, Poljak M, Ogilvie G, Koliopoulos G, Naucler P, Sankaranarayanan R, Peto J (2012) Evidence regarding human papillomavirus testing in secondary prevention of cervical cancer. Vaccine 30(Suppl 5): F88-F99.

Arbyn M, Verdoodt F, Snijders PJF, Verhoef VMJ, Suonio E, Dillner L, Minozzi S, Bellisario C, Banzi R, Zhao F-H, Hillemanns P, Anttila A (2014) Accuracy of human papillomavirus testing on self-collected versus clinician-collected samples: a meta-analysis. Lancet Oncol 15: 172-183.

Van Baars R, Bosgraaf RP, ter Harmsel BWA, Melchers WJG, Quint WGV, Bekkers RLM (2012) Dry storage and transport of a cervicovaginal self-sample by use of the Evalyn Brush, providing reliable human papillomavirus detection combined with comfort for women. J Clin Microbiol 50: 3937-3943.

Bais AG, van Kemenade FJ, Berkhof J, Verheijen RHM, Snijders PJF, Voorhorst F, Babović M, van Ballegooijen M, Helmerhorst TJM, Meijer CJLM (2007) Human papillomavirus testing on self-sampled cervicovaginal brushes: an effective alternative to protect nonresponders in cervical screening programs. Int J Cancer 120: 1505-1510.

Belinson JL, Hu S, Niyazi M, Pretorius RG, Wang H, Wen C, Smith JS, Li J, Taddeo FJ, Burchette RJ, Qiao Y-L (2010) Prevalence of type-specific human papillomavirus in endocervical, upper and lower vaginal, perineal and vaginal self-collected specimens: Implications for vaginal selfcollection. Int J Cancer 127: 1151-1157.

Boutron I, Moher D, Altman DG, Schulz KF, Ravaud P. CONSORT Group (2008) Extending the CONSORT statement to randomized trials of nonpharmacologic treatment: explanation and elaboration. Ann Intern Med 148: 295-309.

Broberg G, Gyrd-Hansen D, Miao Jonasson J, Ryd M-L, Holtenman M, Milsom I, Strander B (2014) Increasing participation in cervical cancer screening: Offering a HPV self-test to long-term non-attendees as part of RACOMIP, a Swedish randomized controlled trial. Int J Cancer 134: 2223-2230.

Cerigo H, Coutlée F, Franco EL, Brassard P (2012) Dry self-sampling versus provider-sampling of cervicovaginal specimens for human papillomavirus detection in the Inuit population of Nunavik, Quebec. J Med Screen 19: $42-48$.

Darlin L, Borgfeldt C, Forslund O, Hénic E, Dillner J, Kannisto P (2013a) Vaginal self-sampling without preservative for human papillomavirus testing shows good sensitivity. J Clin Virol 56: 52-56.

Darlin L, Borgfeldt C, Forslund O, Hénic E, Hortlund M, Dillner J, Kannisto P (2013b) Comparison of use of vaginal HPV self-sampling and offering flexible appointments as strategies to reach long-term non-attending women in organized cervical screening. J Clin Virol 58: 155-160.

Duport N, Salines E, Grémy I (2014) [First results of the experimental evaluation of the French organized cervical cancer screening program, 2010-2012]. Bull Epidémiol Hebd 13-14-15: 228-234.

Eperon I, Vassilakos P, Navarria I, Menoud P-A, Gauthier A, Pache J-C, Boulvain M, Untiet S, Petignat P (2013) Randomized comparison of vaginal self-sampling by standard vs. dry swabs for human papillomavirus testing. BMC Cancer 13: 353.

Ferlay J, Soerjomataram I, Ervik M, Dikshit R, Eser S, Mathers C, Rebelo M, Parkin DM, Forman D, Bray F (2013) GLOBOCAN 2012 v1.0, Cancer Incidence and Mortality Worldwide: IARC CancerBase No. 11. http://globocan.iarc.fr. accessed 29 January 2014.

Fontaine V, Mascaux C, Weyn C, Bernis A, Celio N, Lefèvre P, Kaufman L, Garbar C (2007) Evaluation of combined general primer-mediated PCR sequencing and type-specific PCR strategies for determination of human papillomavirus genotypes in cervical cell specimens. J Clin Microbiol 45: 928-934.

French National Authority for Health (2002) [Follow-up Guidelines for a Patient With an Abnormal Pap Smear Test Result. 2002 Updated Data].

French National Authority for Health (2012) Choices in Methods for Economic Evaluation (Department of Economics and Public Health Assessment).

Gakidou E, Nordhagen S, Obermeyer Z (2008) Coverage of cervical cancer screening in 57 countries: low average levels and large inequalities. PLoS Med 5: e132.

Giorgi Rossi P, Marsili LM, Camilloni L, Iossa A, Lattanzi A, Sani C, Di Pierro C, Grazzini G, Angeloni C, Capparucci P, Pellegrini A, Schiboni ML, Sperati A, Confortini M, Bellanova C, D’Addetta A, Mania E, Visioli CB, Sereno E, 
Carozzi F (2011) The effect of self-sampled HPV testing on participation to cervical cancer screening in Italy: a randomised controlled trial (ISRCTN96071600). Br J Cancer 104: 248-254.

Gök M, Heideman DAM, van Kemenade FJ, Berkhof J, Rozendaal L, Spruyt JWM, Voorhorst F, Beliën JAM, Babovic M, Snijders PJF, Meijer CJLM (2010) HPV testing on self collected cervicovaginal lavage specimens as screening method for women who do not attend cervical screening: cohort study. BMJ 340: c1040.

Gök M, van Kemenade FJ, Heideman DAM, Berkhof J, Rozendaal L, Spruyt JWM, Beliën JAM, Babovic M, Snijders PJF, Meijer CJLM (2012) Experience with high-risk human papillomavirus testing on vaginal brush-based self-samples of non-attendees of the cervical screening program. Int J Cancer 130: 1128-1135.

Goldie SJ, Kim JJ, Wright TC (2004) Cost-effectiveness of human papillomavirus DNA testing for cervical cancer screening in women aged 30 years or more. Obstet Gynecol 103: 619-631.

Gravitt PE, Rositch AF (2014) HPV self-testing and cervical cancer screening coverage. Lancet Oncol 15: 128-129.

Haguenoer K, Giraudeau B, Gaudy-Graffin C, de Pinieux I, Dubois F, Trignol-Viguier N, Viguier J, Marret H, Goudeau A (2014) Accuracy of dry vaginal self-sampling for detecting high-risk human papillomavirus infection in cervical cancer screening: a cross-sectional study. Gynecol Oncol 134: 302-308.

Hoffmann TC, Glasziou PP, Boutron I, Milne R, Perera R, Moher D, Altman DG, Barbour V, Macdonald H, Johnston M, Lamb SE, Dixon-Woods M, McCulloch P, Wyatt JC, Chan A-W, Michie S (2014) Better reporting of interventions: template for intervention description and replication (TIDieR) checklist and guide. BMJ 348: g1687.

IARC (2005) IARC handbooks of cancer prevention: cervix cancer screening.

Lăără E, Day NE, Hakama M (1987) Trends in mortality from cervical cancer in the Nordic countries: association with organised screening programmes. Lancet 1: 1247-1249.

Muñoz N, Bosch FX, de Sanjosé S, Herrero R, Castellsagué X, Shah KV, Snijders PJF, Meijer CJLM (2003) Epidemiologic classification of human papillomavirus types associated with cervical cancer. $N$ Engl J Med 348: 518-527.

Racey CS, Withrow DR, Gesink D (2013) Self-collected HPV testing improves participation in cervical cancer screening: a systematic review and metaanalysis. Can J Public Health 104: e159-e166.

Safaeian M, Herrero R, Hildesheim A, Quint W, Freer E, Van Doorn L-J, Porras C, Silva S, González P, Bratti MC, Rodriguez AC, Castle P (2007) Comparison of the SPF10-LiPA system to the Hybrid Capture 2 Assay for detection of carcinogenic human papillomavirus genotypes among 5,683 young women in Guanacaste, Costa Rica. J Clin Microbiol 45: 1447-1454. Sancho-Garnier H, Tamalet C, Halfon P, Leandri FX, Le Retraite L, Djoufelkit K, Heid P, Davies P, Piana L (2013) HPV self-sampling or the Pap-smear: a randomized study among cervical screening nonattenders from lower socioeconomic groups in France. Int J Cancer 133: 2681-2687.

Schmeink CE, Bekkers RLM, LFAG Massuger, Melchers WJG (2011) The potential role of self-sampling for high-risk human papillomavirus detection in cervical cancer screening. Rev Med Virol 21: 139-153.

Snijders PJF, Verhoef VMJ, Arbyn M, Ogilvie G, Minozzi S, Banzi R, van Kemenade FJ, Heideman DAM, Meijer CJLM (2013) High-risk HPV testing on self-sampled versus clinician-collected specimens: a review on the clinical accuracy and impact on population attendance in cervical cancer screening. Int J Cancer 132: 2223-2236.

Solomon D, Davey D, Kurman R, Moriarty A, O'Connor D, Prey M, Raab S, Sherman M, Wilbur D, Wright Jr T, Young N (2002) The 2001 Bethesda System: terminology for reporting results of cervical cytology. JAMA 287: 2114-2119.

Szarewski A, Cadman L, Mesher D, Austin J, Ashdown-Barr L, Edwards R, Lyons D, Walker J, Christison J, Frater A, Waller J (2011) $\mathrm{HPV}$ self-sampling as an alternative strategy in non-attenders for cervical screening - a randomised controlled trial. Br J Cancer 104: 915-920.

Tamalet C, Richet H, Carcopino X, Henry M, Leretraite L, Heid P, Leandri F-X, Sancho-Garnier H, Piana L (2010) Testing for human papillomavirus and measurement of viral load of HPV 16 and 18 in self-collected vaginal swabs of women who do not undergo cervical cytological screening in Southern France. J Med Virol 82: 1431-1437.

Virtanen A, Anttila A, Luostarinen T, Nieminen P (2011a) Self-sampling versus reminder letter: effects on cervical cancer screening attendance and coverage in Finland. Int J Cancer 128: 2681-2687.

Virtanen A, Nieminen P, Luostarinen T, Anttila A (2011b) Self-sample HPV tests as an intervention for nonattendees of cervical cancer screening in Finland: a randomized trial. Cancer Epidemiol Biomarkers Prev 20: 1960-1969.

Walboomers JM, Jacobs MV, Manos MM, Bosch FX, Kummer JA, Shah KV, Snijders PJ, Peto J, Meijer CJ, Munoz N (1999) Human papillomavirus is a necessary cause of invasive cervical cancer worldwide. J Pathol 189: 12-19.

Wikström I, Lindell M, Sanner K, Wilander E (2011) Self-sampling and HPV testing or ordinary Pap-smear in women not regularly attending screening: a randomised study. Br J Cancer 105: 337-339.

Zhang S-K, Ci P-W, Velicer C, Kang L-N, Liu B, Cui J-F, Chen F, Zhang X, Chang IJ, Roberts CC, Smith JS, Chen W, Qiao Y-L (2014) Comparison of HPV genotypes and viral load between different sites of genital tract: the significance for cervical cancer screening. Cancer Epidemiol 38: 168-173.

This work is published under the standard license to publish agreement. After 12 months the work will become freely available and the license terms will switch to a Creative Commons AttributionNonCommercial-Share Alike 3.0 Unported License.

Supplementary Information accompanies this paper on British Journal of Cancer website (http://www.nature.com/bjc) 